\title{
THE AIR OXIDATION OF 4,6-DI (2-PHENYL-2-PROPYL) PYROGALLOL. SPECTROSCOPIC AND KINETIC STUDIES OF THE INTERMEDIATES.
}

\author{
by \\ HENRY I. ABRASH \\ Department of Chemistry, Carlsberg Laboratory \\ Gamle Carlsbergvej 10 - DK-2500 Copenhagen, Valby' \\ 1) Current address: Department of Chemistry, California State University at Northridge, \\ Northridge, California 91324, USA \\ Key words: 4,6-di (2-phenyl-2-propyl) pyrogallol, \\ consecutive reactions, oxidation, oxygen, $\mathrm{pH}$, quinone, semiquinone, spectra
}

\begin{abstract}
Two colored extinction bands, one with $\lambda_{\max }$ near $520 \mathrm{~nm}$ and the other near $770 \mathrm{~nm}$, form and decay during air oxidations of 4,6-di(2-phenyl-2-propyl) pyrogallol in alkaline methanol. The $770 \mathrm{~nm}$ band appears to be due to the semiquinone monoanion while the extinction near $500 \mathrm{~nm}$ is thought to be due to both the semiquinone and 3-hydroxy-o-quinone. Although the rates of formation and decay of the two bands are indistinguishable in the presence of excess dissolved oxygen, the $770 \mathrm{~nm}$ band disappears slightly before the $500 \mathrm{~nm}$ extinction when the pyrogallol reactant is initially in excess of the dissolved oxygen. Except at high methoxide concentrations, the kinetics indicate a system of two consecutive reactions with pseudo first-order rate constants $\mathrm{k}_{1}$ and $\mathrm{k}_{2}$. The $\mathrm{pH}$ ' dependence of $k_{1}$ indicates that the neutral pyrogallol, its monoanion and dianion all react, the rate increasing with the negative charge of the species. The $\mathrm{k}_{2} / \mathrm{k}_{1}$ ratio is constant at 5 from $\mathrm{pH}^{\prime} 11$ to 16 . Extinction coefficients at both wavelengths increase with $\mathrm{pH}^{\text {'. The }} 770 \mathrm{~nm}$ extinction disappears immediately after acidification while the $500 \mathrm{~nm}$ extinction decays at a rate consistent with oxidation. The rate constants $k_{1}$ and $k_{2}$ are insensitive to changes in pyrogallol concentrations, indicating an absence of irreversible semiquinone disproportionations. Increased oxygen concentration raises $k_{1}$ and $k_{2}$ to the same extent.
\end{abstract}

\section{INTRODUCTION}

There are many reports of colored intermediates of pyrogallol oxidations. Pyrogallol forms a green intermediate during air oxidation in alkaline solutions $(17,18)$, and peroxidase catalyzed oxidation of pyrogallol at neutral $\mathrm{pH}$ produces a transient extinction at $600 \mathrm{~nm}(20)$.
Air oxidation of methyl gallate in aqueous ammonia is accompanied by a transient rose color $(13)$. Several authors $(9,24)$ have described a violet color during air oxidation of 4,6-di-tert-butylpyrogallol and 4,6-di(2-phenyl2-propyl)pyrogallol (2) (Fig. 1, I). SALFELD (23) has recorded the spectrum of a violet in- 


\section{Molecular Structures}<smiles>[R]c1cc([R])c(O)c(O)c1O</smiles><smiles>[R]C1=CC([R])=C(C(=O)O)O[C@H]1O</smiles><smiles>[R]C1=CC([R])=C(O)C(=O)C1=O</smiles>

III

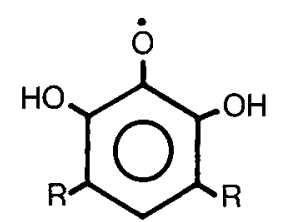

IV<smiles>[R]CC(C)(C)C</smiles>

Figure 1. Structures of molecules involved in this study.

I. 4,6-di(2-phenyl-2-propyl)pyrogallol; II. 3,5-di(2phenyl-2-propyl)-2-pyrone-6-carboxylic acid;

III. quinone derived from 4,6-di(2-phenyl-2-propyl)pyrogallol;

IV. semiquinone derived from 4,6-di(2-phenyl-2-propyl)pyrogallol.

termediate, presumably a 3-hydroxy-o-quinone, formed by silver oxide oxidation of 4,6di-tert-butylpyrogallol in carbon tetrachloride. chloride.

Spectroscopic studies of these intermediates and measurement of their rates of formation and decay can yield important information concerning the mechanism of pyrogallol oxidations. The current work describes the kinetics of the spectroscopic changes accompanying the air oxidation of 4,6-di(2-phenyl-2-propyl)pyrogallol in alkaline methanol and the effects of $\mathrm{pH}$ and reactant concentrations on the reaction rates and intermediate spectra.

\section{MATERIALS AND METHODS}

\subsection{Reagents and solvents.}

4,6-Di(2-phenyl-2-propyl)pyrogallol, m.p. $119.5-120^{\circ} \mathrm{C}$, was prepared from pyrogallol and 2-phenylpropene by the method of JONSSON (16).

The following reagents were used in kinetic studies: analytic grade methanol and analytic grade 5,5-diethylbarbituric acid, E. Merck, Darmstadt; analytic grade phthalic acid and practical grade sodium methoxide, Fluka AB, Switzerland; oxygen and nitrogen, Dansk Ilt og Brint Fabrik A/S, Copenhagen.

\subsection{Methanolic buffers and pH' measurement.}

The alkalinity of all methanolic solutions, both sodium methoxide and buffer solutions, is reported as $\mathrm{pH}$ ' values - the negative logarithm of the activity of protonated solvent (lyonium ion) compared to unit activity of an ideal lyonium ion in the same solvent (5).

The molarity of a $0.195 \mathrm{M}$-sodium methoxide stock solutions in methanol was determined by adding $50 \mu$ lof this solution to an aqueous solution containing $50 \mu \mathrm{l}$ of $0.196 \mathrm{M}$-phthalic acid in methanol and titrating to the second inflection point of phthalic acid. The titrations were performed by the stepped titration method with $0.1030 \mathrm{M}$-aqueous $\mathrm{NaOH}$. The automatic titrator (Radiometer, Copenhagen) consisted of a PHM 64 research pH meter with a G 2222C glass electrode and a K 130 calomel electrode, a TTT 60 titrator, a ABU 13 autoburet and a REC 61 Servograph recorder equipped with a REA 160 Titrigraph module and REA 300 Titrigraph pen drive. The $\mathrm{pH}$ meter was standardized at $\mathrm{pH} 7.00$.

This stock sodium methoxide solution was used to prepare a series of more dilute methoxide solutions ranging down to $0.0049 \mathrm{M}$. The $\mathrm{pH}^{\prime}$ values of the sodium methoxide solutions in the kinetic runs were estimated assuming ideal solutions and a $\mathrm{pK}_{\text {autoprotolysis }}$ value of 16.7 for methanol (6). Corrections were made for dilution by the reactant stock solutions and for neutralization by the pyrogallol reactant, assuming that this compound acts as a monoprotic acid in the more dilute sodium methoxide solutions. 
Methanolic phthalate buffers covering the pH' range 11-12.1 were prepared according to the data of Broser and Fleischauer (8). The appropriate amount of $0.195 \mathrm{M}$-phthalic acid stock solution was mixed with $2.50 \mathrm{ml} 0.196$ $\mathrm{M}$-sodium methoxide and the solution diluted to $25.0 \mathrm{ml}$.

Methanolic veronal buffers covering the $\mathrm{pH}$ ' range 12-13.5 were prepared by dissolving various amounts of 5,5-diethylbarbituric acid in $22.5 \mathrm{ml}$ methanol and adding $2.50 \mathrm{ml} 0.195$ M-sodium methoxide. Although this procedure probably forms sodium 5,5-diethylbarbiturate in excess of its solubility in methanol, the solutions were stable for several days without precipitation or $\mathrm{pH}$ ' change. The $\mathrm{pH}$ ' values of the veronal buffers were determined by adding small amounts of bromthymol blue solution and recording the ratio of the extinction at $617 \mathrm{~nm}$ (the $\lambda_{\max }$ of the conjugate base of bromthymol blue) and $493 \mathrm{~nm}$ (the isosbestic point for the acid-base reaction). Experiments with phthalate buffers showed the validity of the equation:

$a_{H}^{\prime}=1.67 \times 10^{-12}\left[\frac{6.77}{r-0.22}-1\right]$

where $\mathrm{a}_{\mathrm{H}}$ is the lyonium ion activity defined in terms of an ideal methanolic solution and $r$ the ratio of the extinctions at 617 and $493 \mathrm{~nm}$. This equation was used to calculate the $\mathrm{pH}$ ' values of veronal buffers in the 12-12.6 range. From these $\mathrm{pH}^{\prime}$ values, we calculate a $\mathrm{K}_{\mathrm{a}}^{\prime}$ value of $2.5 \times 10^{-13}$ for 5,5-diethylbarbituric acid in methanol and use this value to compute the $\mathrm{pH}^{\prime}$ values of more alkaline veronal buffers. The $\mathrm{K}_{\mathrm{a}}$ value agrees closely with that reported by TABAGUA (25). The use of this somewhat imprecise method to estimate $\mathrm{pH}$ ' values of veronal buffers in the 12.6-13.5 range is justified by the relative insensitivity of the reaction rates to $\mathrm{pH}^{\prime}$ in this range. (See section 3 ).

\subsection{Kinetics.}

Spectroscopic changes occuring during the air oxidation of 4,6-di(2-phenyl-2-propyl)pyrogallol were recorded on a Cary 118 UV-visible spectrophotometer (Varian Corp.,
Monrovia, Calif.). A rapid mixing device of the type described by AULD and FRENCH (4) was used to follow the fast reactions in more alkaline solutions. This apparatus, thermostatted at $25^{\circ} \mathrm{C}$ by Hetofrig Circulating Thermostat (Birkerød, Denmark), contained $1.0 \mathrm{ml}$ of the appropriate methanolic solution, and this solution was stirred for several minutes before initiating the reaction to assure equilibration of temperature and gas solubility. The spectrophotometer was set to run at a constant wavelength with the pen scale chosen so that the expected extinction would rise above two tenths full-scale deflection but not reach full deflection. The chart speed was chosen to give a convenient display of the data, the most rapid speed being one inch per ten seconds. After the pen had been brought to zero with the zero suppression switch and balance adjust control, the extinction was recorded and a predetermined volume (usually $200 \mu \mathrm{l}$ ) of an approximately $2.5 \mathrm{mM}$ solution of 4,6-di(2-phenyl-2-propyl)pyrogallol in nitrogen purged methanol was injected into the reaction cell from a Hamilton 1001 Microlyter syringe (Whittier, Calif.) through a teflon tube. Extinction was recorded until it had fallen to less than one tenth full scale. In experiments in which the extinction did not rise above 0.3 full scale, extinction was recorded until it decreased to 0.05 full scale. Between experiments, the Microlyter syringe was refilled from a reservoir consisting of a $10 \mathrm{ml}$ syringe via a Hamilton 4LLLF4 four-way valve. The solution from the previous experiment was removed from the reaction cell by means of a syringe connected to the lower part of the cell, and the cell was washed with one $\mathrm{ml}$ of the solution to be used in the next experiment.

Slower reactions at lower pH' values were measured in a thermostatted silica cell against a reference cell containing methanol. With $3.0 \mathrm{ml}$ of the methanolic buffer in the sample cell, the pen was brought to zero with the balance control. The cell compartment cover was then removed, the desired volume (usually $50 \mu \mathrm{l}$ ) of ca $25 \mathrm{mM}$ reactant stock solution added from a Levy-Lang micro pipet, the solution stirred with a teflon rod, and the cell compartment cover quickly replaced. Extinction was 
recorded within ten seconds of the start of the reaction.

Experiments were performed with air-saturated or oxygen-saturated solutions. Oxygen-saturated solutions were prepared by bubbling oxygen through the sodium methoxide or buffer solution for at least ten minutes just before the experiment, and the spectrophotometer cell compartment was flushed with oxygen during the experiment. Estimates of oxygen concentrations are based on data in the International Critical Tables (15). In all cases, the initial concentration of dissolved oxygen was at least three times that of the pyrogallol reactant.

In spite of efforts to prevent exposure of the pyrogallol reactant stock solutions to air, these solutions darkened in the course of several hours due to exposure during transfer or air leaks in the reservoir syringe. In later experiments, stock solutions were discarded when they darkened enough to produce high initial extinction values. We have reported data from earlier runs with partially oxidized stock solutions after correcting for this oxidation. (See section 2.4.).

Some experiments involve rapid acidification of the solution after the colored intermediates had accumulated at high $\mathrm{pH}^{\prime}$. In the experiment shown in Fig. 4, $200 \mu \mathrm{l}$ of reactant stock solution was added to $1.0 \mathrm{ml}$ of 0.0023 M-sodium methoxide. After about 30 seconds, $25 \mu \mathrm{l}$ of $28 \mathrm{mg} / \mathrm{ml}$. phthalic acid in methanol was added through a hole in the top of the fast mixing apparatus, the hole quickly closed with a rubber stopper and the extinction recorded. For comparison, the phthalic acid was first mixed with the sodium methoxide and the rate of reaction in the resulting buffer measured by the fast reaction method.

\subsection{Data analysis.}

Except for runs at sodium methoxide concentrations above $0.04 \mathrm{M}$, the data fit the equation for the formation of an intermediate in a system of two pseudo first-order reactions.
$\mathrm{A} \stackrel{\mathrm{k}_{1}}{\longrightarrow} \mathrm{B} \stackrel{\mathrm{k}_{2}}{\longrightarrow}$ colorless product

(B) $=\frac{k_{1}(A)_{0}}{k_{2}-k_{1}}\left(e^{-k_{1} t}-e^{-k_{2} t}\right)$

or

$E_{\lambda}=\frac{k_{1} \varepsilon \lambda^{l}(A)_{0}}{k_{2}-k_{1}}\left(e^{-k_{1} t}-e^{-k_{2} t}\right)$

(eqn.1)

where $A$ is 4,6-di(2-phenyl-2-propyl)pyrogallol, $B$ the colored intermediate, $E_{\lambda}$ its extinction and $\varepsilon_{\lambda}$ its molar extinction coefficient at the wavelength of the experiment, 1 the path length of the cell and $k_{1}$ and $k_{2}$ the two pseudo first-order rate constants. Experiments at methoxide concentrations greater than $0.04 \mathrm{M}$ deviate from eqn. 1 by showing higher extinctions than predicted at longer reaction times. In other words, $k_{1}$ appears to decrease with time. This effect is independent of the initial concentration of the pyrogallol, so it does not appear to be due to a decrease in the dissolved oxygen concentration with time. While concerned about the significance of this unexplained deviation, we have fit the data at shorter reaction times in these runs to eqn. 1 by a suitable choice of $k_{1}, k_{2}$ and $\varepsilon \lambda$. These parameters were estimated for each run by the least-squares method of Alcock et al. (3).

Kinetic curves for partially oxidized stock solutions of 4,6-di(2-phenyl-2-propyl)pyrogallol had high initial extinctions. These curves were analyzed by extrapolating the extinction back to a corrected zero time and then treating the data as before. This procedure is justified because the integrated rate equation for a case in which the initial concentration of $B$ is less than $k_{1}(A)_{0} /\left(k_{2}-k_{1}\right)$ is:

(B) $=\frac{\mathrm{k}_{1}(\mathrm{~A})_{0}}{\mathrm{k}_{2}-\mathrm{k}_{1}}\left(\mathrm{e}^{-\mathrm{k}_{1}(\mathrm{t}+\Delta)}-\mathrm{e}^{-\mathrm{k}_{2}(\mathrm{t}+\Delta)}\right)$

where $\Delta$ is the zero time correction. 


\section{RESULTS}

The air oxidation of 4,6-di(2-phenyl-2-propyl)pyrogallol in strongly alkaline methanolic solution is accompanied by the transient formation of two broad extinction bands in the visible region, one with $\lambda_{\max }$ near $520 \mathrm{~nm}$, the other at about $770 \mathrm{~nm}$ (Fig. 2). Strong product extinc-

\section{Intermediate Spectra}

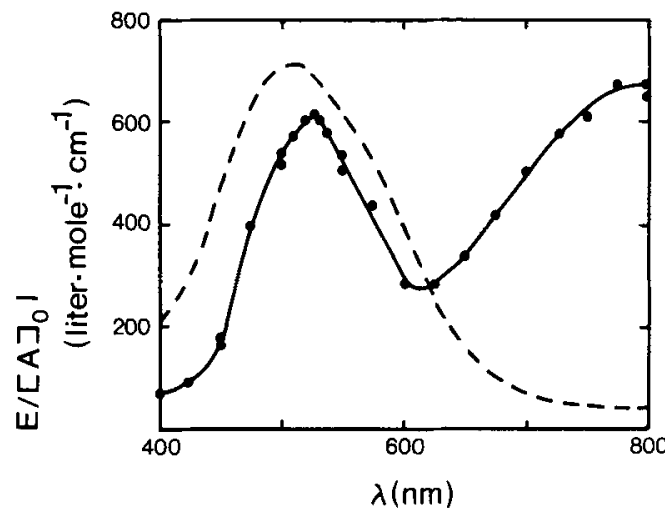

Figure 2. Spectra of the intermediates of air oxidation of 4,6-di(2-phenyl-2-propyl)pyrogallol.

-: $E_{\max } /(A)_{0} 1$ in air satureted $0.02 \mathrm{M}$-sodium methoxide. $(A)_{0}=0.40 \mathrm{mM}$. Broken line: spectrum of intermediate formed when $0.23 \mathrm{~mm}-4,6-\mathrm{di}(2-$ phenyl-2-propyl)pyrogallol was oxidized for 30 seconds in $0.002 \mathrm{M}$-sodium methoxide and then neutralized with phthalic acid.

tion in the ultraviolet region hindered attempts to study intermediate extinctions below $400 \mathrm{~nm}$. Extinction at $250 \mathrm{~nm}$ does rise to a maximum after about thirty seconds and then decays during the air oxidation in 0.002 M-sodium methoxide, and this transient extinction is stronger than those at 200 and $275 \mathrm{~nm}$. Product extinction dominates between 300 and $350 \mathrm{~nm}$, and the extinction at these wave lengths increases steadily during oxidation.

In the presence of excess dissolved oxygen, the two visible intermediate extinction bands form and decay with indistinguishable rates over the entire range of $\mathrm{pH}^{\prime}$, oxygen concentration and pyrogallol reactant concentration studied. With the exception of experiments at sodium methoxide concentrations of $0.04 \mathrm{M}$ or greater, the extinction versus time curves are adequately described by eqn. 1 . The curves at high methoxide concentration show decreasing rate constants for decay during the latter part of the reaction. Nevertheless, we have fit the early portions of these curves to eqn. 1 and ignored the deviations at longer times. While the values obtained for the kinetic constants in these experiments merit some scepticism, we feel that they indicate real trends in the high $\mathrm{pH}^{\prime}$ range.

In applying eqn. 1, we have assumed that the larger of the two rate constants is $k_{2}$ and the smaller $k_{1}$. The justification for this assumption of a slow reaction followed by a fast one is the observed change in extinction in solutions in which the pyrogallol reactant is in excess of the dissolved oxygen (see Section 4). In such cases, an initial rapid increase and decrease of extinction is followed by a slower formation and decay of the intermediates.

Figure 3 shows the influence of $\mathrm{pH}^{\prime}$ on $\mathrm{k}_{1}$ and $k_{2}$ and the extinction coefficients for reactions in air-saturated methanol at $25^{\circ} \mathrm{C}$. There is no significant difference between the rate constants determined at $500 \mathrm{~nm}$ and those obtained under identical conditions at $770 \mathrm{~nm}$. The values of $k_{1}$ at both wavelengths fit a curve describing a mechanism in which neutral reactant, monoanion and dianion react with pseudo first-order rate constants $\mathrm{k}^{\circ}, \mathrm{k}^{-}, \mathbf{k}=$ respectively:

$$
k_{1}=\frac{k^{\circ}\left(H^{+}\right)^{2}+k^{-} K_{1}\left(H^{+}\right)+k=K_{1} K_{2}}{\left(H^{+}\right)^{2}+K_{1}\left(H^{+}\right)+K_{1} K_{2}}
$$

where $K_{1}$ and $K_{2}$ are the first and second dissociation constants. The following values give a reasonable fit of the data.

$$
\begin{aligned}
& \mathrm{k}^{\circ}=4 \times 10^{-4} \mathrm{sec}^{-1} ; \mathrm{k}^{-}=0.016 \mathrm{sec}^{-1} \\
& \mathrm{k}=0.20 \mathrm{sec}^{-1} \\
& \mathrm{~K}_{1}=2.5 \times 10^{-13} ; \mathrm{K}_{2}=1 \times 10^{-16}
\end{aligned}
$$

The data presented in Fig. $3 \mathrm{~b}$ indicate that $\mathrm{k}_{2} / \mathrm{k}_{1}$ ratios are independent of $\mathrm{pH}$ '. This can be seen from the fit of the $k_{2}$ values to a theoretical curve calculated from assumption $\mathrm{k}_{2}=5 \mathrm{k}_{1}$ where $k_{1}$ is calculated from eqn. 2 . While there 


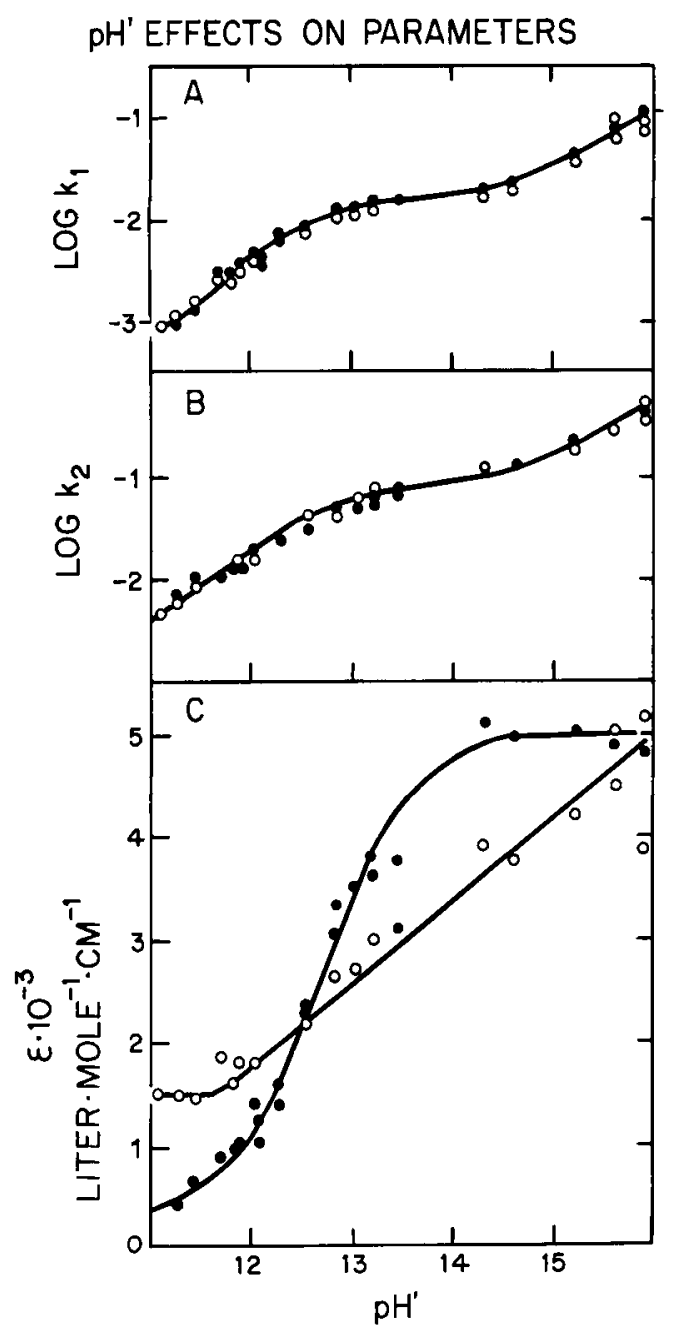

Figure 3. The effect of $\mathrm{pH}^{\prime}$ on $\mathrm{k}_{1}, \mathrm{k}_{2}$ and extinction coefficients. All experiments were performed in air-saturated methanol at $25^{\circ} \mathrm{C}$. o: results at $500 \mathrm{~nm}$; - results at $770 \mathrm{~nm}$. 3a: $\log \mathrm{k}_{1}$ versus pH'. The solid curve is drawn according to eqn. 2 . for the parameters $\mathrm{k}^{0}=4 \times 10^{-4} \mathrm{sec}^{-1}, \mathrm{k}^{-}=0.016 \mathrm{sec}^{-1}, \mathrm{k}^{=}=0.20$ $\mathrm{sec}^{-1}, \mathrm{~K}_{1}=2.5 \times 10^{-13}, \mathrm{~K}_{2}=1 \times 10^{-16} ; 3 \mathrm{~b}$ : $\log \mathrm{k}_{2}$ versus $\mathrm{pH}^{\prime}$. The solid curve is drawn for $\mathrm{k}_{2}=5 \mathrm{k}_{1}$ where $\mathrm{k}_{1}$ is given by eqn. 2 and the parameters listed in 3a.; $3 \mathrm{c}$ : extinction coefficients versus $\mathrm{pH}$ '. The extinction coefficients are calculated according to eqn. 3 assuming $r=5$. is considerable scatter in the individual estimates of $\mathrm{k}_{2} / \mathrm{k}_{1}$, all values for this ratio are in the 1.9-7.6 range, and 40 out of 42 fall in the 3-7 range. There is no apparent trend in the individual estimates with $\mathrm{pH}^{\prime}$.

The maximum extinction observed during a run $\left(\mathrm{E}_{\max }\right)$ increases with $\mathrm{pH}$ ' both at $500 \mathrm{~nm}$ and $770 \mathrm{~nm}$. A plot of $\varepsilon$ versus pH' (Fig. 3c) shows these effects. In computing $\varepsilon$, we have assumed a constant $k_{2} / k_{1}$ ratio ( $r$ ) equal to five and used the equations (11).

$$
\begin{aligned}
& (B)_{\max }=(A)_{0} r^{-r / r-1} \\
& \varepsilon=\frac{E_{\max }}{(B)_{\max } 1}=\frac{E_{\max ^{r} r^{\mathrm{r} / \mathrm{r}-1}}}{(\mathrm{~A})_{0} 1}
\end{aligned}
$$

in order to avoid scatter due to random variations in the individual estimates of $r$. The $770 \mathrm{~nm}$ intermediate is completely absent at low $\mathrm{pH}$ ', the only extinction at this wavelength being due to the $500 \mathrm{~nm}$ intermediate. The extinction coefficient at $770 \mathrm{~nm}$ increases to a constant value of $5.0 \times 10^{3}$ liter.mole ${ }^{-1} \cdot \mathrm{cm}^{-1}$ above $\mathrm{pH}^{\prime} 14$, and the inflection point for this increase occurs at about $\mathrm{pH}$ ' 12.7. Extinction at $500 \mathrm{~nm}$ is constant at an $\varepsilon$ value of $1.5 \times 10^{3}$ liter $\cdot \mathrm{mole}^{-1} \cdot \mathrm{cm}^{-1}$ below $\mathrm{pH}^{\prime} 12$ but gradually rises with increasing $\mathrm{pH}^{\prime}$ to about $5 \times 10^{3}$ liter $\cdot \mathrm{mole}^{-1} \cdot \mathrm{cm}^{-1}$ in the $15-16 \mathrm{pH}$ range. It is not clear from the data whether this is a steady increase or whether it involves an inflection point.

The $770 \mathrm{~nm}$ intermediate reacts very rapidly with $\mathrm{H}^{+}$. This is shown by an experiment in which the intermediates were allowed to accumulate by oxidation for thirty seconds in $0.002 \mathrm{M}$-sodium methoxide and the solution was then acidified by addition of methanolic phthalic acid. Rapid acidification causes an immediate loss of extinction at $770 \mathrm{~nm}$ (Fig. 2) even though the rate of oxidative decay of this intermediate is slow at low $\mathrm{pH}^{\prime}$. It also appears that the $770 \mathrm{~nm}$ intermediate forms by a rapid reaction between methoxide ion and an intermediate formed in neutral solution. To demonstrate this, we allowed a neutral solution of 4,6-di(2-phenyl-2-propyl) pyrogallol to slowly oxidize and then added it to $\mathrm{pH}^{\prime} 11.7$ phthalate buffer in one case and 0.002 
Decay of $E_{500}$ in acidified solutions

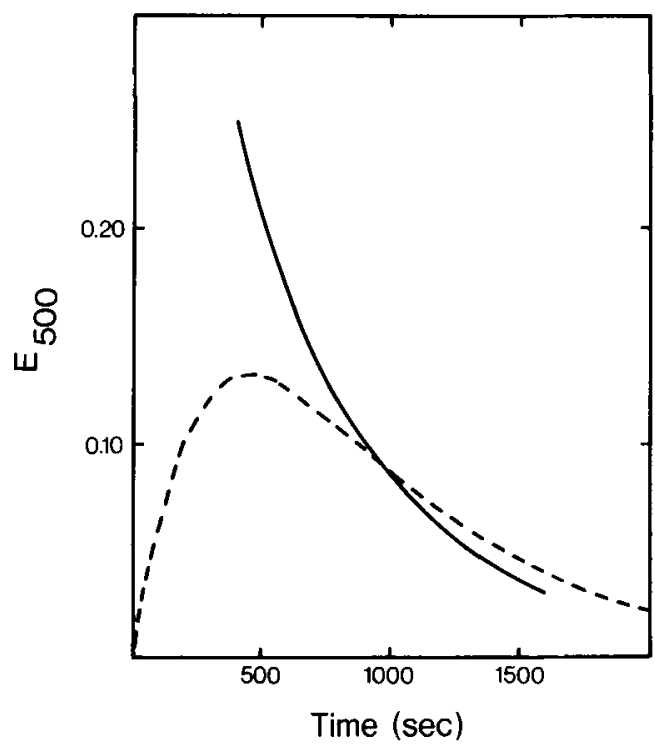

Figure 4. Change in $e_{900}$ after acidification of a partially oxidized solution.

Solid line: $\mathrm{E}_{900}$ after $3.0 \mathrm{ml}$. of $0.38 \mathrm{~mm}-4,6$-di(2-phenyl-2-propyl) pyrogallol was oxidized for 30 seconds in $0.0023 \mathrm{M}$-sodium methoxide and then neutralized with $25 \mu \mathrm{l} 0.20 \mathrm{M}$-phthalic acid. The time scale has been displaced 400 seconds to the right. Broken line: $0.38 \mathrm{~mm}$-pyrogallol reactant in the buffer formed from $3.0 \mathrm{ml} 0.0023 \mathrm{M}$-sodium methoxide and $25 \mu \mathrm{l} 0.20$ M-phthalic acid.

M-sodium methoxide in another and observed the extinction changes at $770 \mathrm{~nm}$ using fast reaction techniques. In both cases the initial extinction was high, and the extinction reached its maximum more quickly than with fresh reactant stock solutions.

In contrast, the $500 \mathrm{~nm}$ extinction does not respond rapidly to acidification (Fig. 2 and 4). The extinction immediately after acidification of a partially oxidized solution is approximately the same as at high $\mathrm{pH}^{\prime}$ and nearly twice the maximum extinction obtained when the pyrogallol reactant was oxidized in the buffer formed by adding the same amount of phthalic acid to the same volume of sodium methoxide. The constants estimated for oxidation in the low $\mathrm{pH}$ ' buffer are $\mathrm{k}_{1}=0.0013 \mathrm{sec}^{-1}, \mathrm{k}_{2}=0.0039$ $\mathrm{sec}^{-1}$ and $\varepsilon_{300}=1.8 \times 10^{3}$ liter $\cdot \mathrm{mole}^{-1} \cdot \mathrm{cm}^{-1}$. The extinction change after acidification of the partially oxidized solution fits the equation:

$$
E=0.205 e^{-0.0016 t}+0.045 e^{-0.0036 t}
$$

The close agreement between the rate constants for oxidation in the buffer and the exponential terms found in the acidification experiment will be discussed in section 4 .

Table I shows the effect of the initial concentration of 4,6-di(2-phenyl-2-propyl)pyrogallol on the apparent rate constants. Within the limited range of concentration (0.07-0.34 $\mathrm{mm}$ ) allowed by the sensitivity of the spectroscopic method and the requirement of a large excess of dissolved oxygen, the apparent $\mathrm{k}_{1}$ values at both wavelengths and $\mathrm{pH}^{\prime}$ values appear to be independent of reactant concentration. The situation is not as clear for the less precise estimates of $k_{2}$, and we have used two other criteria concerning the constancy of the $k_{2} / k_{1}$ ratio. If this rate is constant, $k_{1}$ should be inversely proportional to the time it takes for the extinction to reach a maximum $\left(t_{\max }\right)$, and $\mathrm{E}_{\max }$ should be proportional to $(\mathrm{A})_{0}$. This seems to be the case for both wavelengths at $\mathrm{pH}^{\prime}$ 13.76. The data at $\mathrm{pH}^{\prime} 11.70$ show a slight increase in $k_{1} t_{\max }$, both at 500 and $770 \mathrm{~nm}$, as reactant concentration decreases. In the case of the $770 \mathrm{~nm}$ intermediate, $\mathrm{E}_{\max }$ appears to be proportional to reactant concentration while $E_{\max }$ at $500 \mathrm{~nm}$ does not rise as much as reactant concentration.

Table II contains data obtained in oxygen-saturated solutions and, for comparison, in air-saturated solutions at the same $\mathrm{pH}^{\prime}$. Increased oxygen concentration increases both rate constants and, to judge from the constancy of $E_{\max }$ and $k_{1} t_{\max }$, both rate constants are affected to the same extent. This increase in rate constant is a factor of about 3.5. While this is considerably less than the 4.8 -fold increase in oxygen concentration predicted by Henry's law, the data are not precise enough to decide whether or not the pseudo first-order rate constants are strictly proportional to the concentration of dissolved oxygen.

The two extinction bands are affected differently by an insufficiency in dissolved oxygen, the extinction at $770 \mathrm{~nm}$ being weaker 
Table I

Efect of concentration of 4,6-di (2-phenyl-2-propyl) pyrogallol on rate constants

\begin{tabular}{l|c|c|c|c|c}
\hline $\begin{array}{l}\mathrm{A})_{\circ} \\
(\mathrm{mM})\end{array}$ & $\begin{array}{c}\mathrm{t}_{\max } \\
(\mathrm{sec})\end{array}$ & $\mathrm{E}_{\max }$ & $\begin{array}{c}\mathrm{k}_{1} \times 10^{2} \\
\left(\mathrm{sec}^{-1}\right)\end{array}$ & $\begin{array}{c}\mathrm{k}_{2} \times 10^{2} \\
\left(\mathrm{sec}^{-1}\right)\end{array}$ & $\begin{array}{c}\varepsilon \times 10^{-3} \\
\left(\operatorname{liter} \times \mathrm{mole}^{-1} \times \mathrm{cm}^{-1}\right)\end{array}$ \\
\hline
\end{tabular}

A. Experiments at $500 \mathrm{~nm}$ $\mathrm{pH}^{\prime} 13.96$

\begin{tabular}{l|l|l|l|l|l}
\hline 0.342 & 30 & 0.164 & $1.11 \pm 0.01$ & $7.9 \pm 0.1$ & $4.77 \pm 0.88$ \\
0.187 & 32 & 0.0960 & $1.11 \pm 0.02$ & $7.2 \pm 0.2$ & $4.7 \pm 0.1$ \\
0.098 & 32 & 0.0495 & $1.22 \pm 0.08$ & $6.3 \pm 0.2$ & $3.9 \pm 0.1$ \\
\hline $\mathrm{pH}^{\prime} 11.70$ & 190 & 0.0850 & $0.251 \pm 0.002$ & $0.97 \pm 0.01$ & $1.54 \pm 0.02$ \\
\hline 0.340 & 220 & 0.0500 & $0.261 \pm 0.003$ & $0.80 \pm 0.01$ & $1.52 \pm 0.02$ \\
0.171 & 240 & 0.0223 & $0.286 \pm 0.008$ & $0.58 \pm 0.02$ & $1.30 \pm 0.05$ \\
0.069 &
\end{tabular}

B. Experiments at $770 \mathrm{~nm}$ $\mathrm{pH}^{\prime} 13.96$

\begin{tabular}{l|l|l|l|l|l}
\hline 0.342 & 35 & 0.217 & $1.18 \pm 0.02$ & $5.6 \pm 0.1$ & $\begin{array}{l}4.5 \pm 0.1 \\
2.11 \pm 0.08 \\
0.187\end{array}$ \\
0.098 & 35 & 0.0930 & $1.70 \pm 0.05$ & $3.7 \pm 0.1$ & $5.8 \pm 0.1$ \\
\hline $\mathrm{pH}^{\prime} 11.70$ & 0.0600 & $1.33 \pm 0.02$ & $5.3 \pm 0.1$ & 3.8 \\
\hline 0.340 & 180 & 0.0410 & $0.281 \pm 0.007$ & $0.96 \pm 0.03$ & $0.68 \pm 0.03$ \\
0.171 & 200 & 0.0235 & $0.45 \pm 0.06$ & $0.5 \pm 0.2$ & $0.4 \pm 0.2$ \\
0.069 & 230 & 0.0096 & $0.271 \pm 0.007$ & $0.58 \pm 0.06$ & $0.58 \pm 0.06$ \\
\hline
\end{tabular}

relative to the $500 \mathrm{~nm}$ band when 4,6-di(2-phenyl-2-propyl)pyrogallol is in excess of dissolved oxygen (Fig. 5). Furthermore, as can be seen from the spectrum recorded at the end of the reaction with oxygen from the atmosphere, the $770 \mathrm{~nm}$ band disappears slightly before the $500 \mathrm{~nm}$ extinction. This effect is visible to the naked eye as a color shift from violet to red shortly before the cessation of oxygen uptake. A similar color change was observed by SCHULzE and Flaig (24) in the case of 4,6-di-tert-butylpyrogallol.

\section{DISCUSSION}

Two broad extinction bands, one with $\lambda_{\max }$ neat $520 \mathrm{~nm}$ and the other near $770 \mathrm{~nm}$, form and decay during the air oxidation of 4,6-di(2-phenyl-2-propyl)pyrogallol in alkaline methanol, and these colored intermediates disappear when oxygen uptake ceases. The extinction band at $520 \mathrm{~nm}$ resembles the spectrum observed by SALFIELD (23) for carbon
Effect of $\mathrm{O}_{2}$ deficiency on Spectra

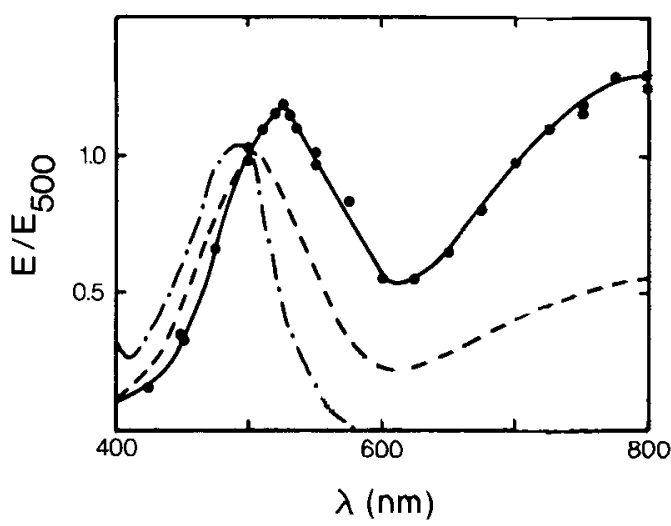

Figure 5. Effect of $\mathrm{O}_{2}$ deficiency on the intermediate spectra.

-: $E / E_{s 00}$ for $E_{\text {max }}$ values when $0.40 \mathrm{~mm}-4,6-\mathrm{di}$ (2-phenyl-2-propyl)pyrogallol was oxidized in 0.02 $\mathrm{M}$-sodium methoxide;------ $\mathrm{E}_{\mathrm{E}} \mathrm{E}_{\mathrm{so0}}$ for 4.6 mM-pyrogallol reactant oxidized in $0.2 \mathrm{M}$-sorium methoxide for seven minutes $\left(E_{500}=0.813\right)$. The initial $\mathrm{O}_{2}$ concentration was $1.6 \mathrm{~mm} ;---.-E / E_{500}$ after 23 minutes oxidation $\left(E_{300}=0.088\right)$. 
Table II

Effect of $\mathrm{O}_{2}$ concentration on rate constants

\begin{tabular}{l|l|l|l|l|l|l}
\hline $\mathrm{pH}^{\prime}$ & solution & $\begin{array}{c}\mathrm{t}_{\max } \\
(\mathrm{sec})\end{array}$ & $\mathrm{E}_{\max }$ & $\begin{array}{c}\mathrm{k}_{1} \times 10^{2} \\
\left(\mathrm{sec}^{-1}\right)\end{array}$ & $\begin{array}{c}\mathrm{k}_{2} \times 10^{2} \\
\left(\mathrm{sec}^{-1}\right)\end{array}$ & $\begin{array}{c}\varepsilon \times 10^{-3} \\
\left(\text { liter }_{\mathrm{mole}} \mathrm{mol}^{-1} \cdot \mathrm{cm}^{-1}\right)\end{array}$ \\
\hline
\end{tabular}

\begin{tabular}{|c|c|c|c|c|c|c|}
\hline \multicolumn{7}{|c|}{ A. Experiments at $500 \mathrm{~nm}$} \\
\hline 13.96 & $\begin{array}{c}\text { air sat. } \\
0.342 \mathrm{mM} \mathrm{A}\end{array}$ & 30 & 0.164 & $1.11 \pm 0.01$ & $7.9 \pm 0.1$ & $4.77 \pm 0.08$ \\
\hline 13.96 & $\begin{array}{c}\mathrm{O}_{2} \text { sat. } \\
0.325 \mathrm{mM} \mathrm{A}\end{array}$ & 11 & 0.176 & $4.3 \pm 0.1$ & $15.9 \pm 0.7$ & $3.3 \pm 0.2$ \\
\hline 11.70 & $\begin{array}{c}\text { air sat. } \\
0.340 \mathrm{mM} \mathrm{A}\end{array}$ & 190 & 0.0850 & $0.251 \pm 0.002$ & $0.97 \pm 0.01$ & $1.54 \pm 0.02$ \\
\hline 11.70 & $\begin{array}{c}\mathrm{O}_{2} \text { sat. } \\
0.325 \mathrm{mM} \text { A }\end{array}$ & 75 & 0.0770 & $0.77 \pm 0.01$ & $2.49 \pm 0.05$ & $1.30 \pm 0.03$ \\
\hline \multicolumn{7}{|c|}{ B. Experiments at $770 \mathrm{~nm}$} \\
\hline 13.96 & $\begin{array}{c}\text { air sat. } \\
0.342 \mathrm{mM} \mathrm{A}\end{array}$ & 35 & 0.217 & $1.18 \pm 0.02$ & $5.6 \pm 0.1$ & $4.5 \pm 0.1$ \\
\hline 13.96 & $\begin{array}{c}\mathrm{O}_{2} \text { sat. } \\
0.325 \mathrm{mM} \mathrm{A}\end{array}$ & 10 & 0.244 & $4.1 \pm 0.1$ & $18.4 \pm 0.9$ & $5.2 \pm 0.3$ \\
\hline 11.70 & $\begin{array}{c}\text { air sat. } \\
0.340 \mathrm{mM} \mathrm{A}\end{array}$ & 180 & 0.0410 & $0.281 \pm 0.007$ & $0.96 \pm 0.03$ & $0.68 \pm 0.03$ \\
\hline 11.70 & $\begin{array}{c}\mathrm{O}_{2} \text { sat. } \\
0.325 \mathrm{mM} \mathrm{A}\end{array}$ & 45 & 0.0476 & $1.23 \pm 0.04$ & $2.7 \pm 0.1$ & $0.61 \pm 0.02$ \\
\hline 11.70 & $0.325 \mathrm{mM} \mathrm{A}$ & 55 & 0.0450 & $1.3 \pm 0.2$ & $1.8 \pm 0.3$ & $0.44 \pm 0.3$ \\
\hline
\end{tabular}

tetrachloride solutions of 4,6-di-tert-butylpyrogallol which had been oxidized by silver oxide. SALFIELD ascribes this spectrum to the corresponding 3-hydroxy-o-quinone on the basis of the solution's infrared spectrum.

Although both extinction bands form and decay with indistinguishable rates over the entire $\mathrm{pH}^{\prime}$ range studied, there is definite evidence that they are not solely due to a single intermediate or two intermediates in rapid equilibrium with each other. The first piece of evidence is the decrease in $\mathrm{E}_{770} / \mathrm{E}_{300}$ ratio near the end of the reaction when the pyrogallol reactant is in excess of dissolved oxygen. The second piece of evidence, involving the difference in the rates of response of the two extinctions to rapid acidification, will be discussed in more detail later.

As Alcock et al. (3) have pointed out, there is an ambiguity in describing extinction versus time curves for the intermediate of two first-order processes since two sets of the parameters $k_{1}, k_{2}$ and $\varepsilon$ fit the experimental curve equally well. The two sets of rate constants differ in that the numerical values of $k_{1}$ and $k_{2}$ are interchanged. If the hypothesis that a fast second step follows a slow initial step is chosen, then the estimate of $\varepsilon$ will be greater than the estimate based on the reverse hypothesis (first step fast, second slow) by the factor $k_{2} / k_{1}$. One solution to this problem would be to measure the rate of consumption of the reactant, but extinctions of the intermediate or products obscure reactant extinction at all wavelengths tried, and we have not developed any other sufficiently rapid technique for measuring the decrease in reactant concentration.

We favor the hypothesis that fast reactant follows an initial slow step because of the 
observation that, when 4,6-di(2-phenyl-2-propyl)pyrogallol is present in excess of dissolved oxygen, a rapid initial increase and decrease in extinction is followed by a slower formation and decay of colored intermediates. The initial rapid changes represent the relatively rapid reactions with dissolved oxygen, and the subsequent slower processes occur as additional oxygen diffuses from the atmosphere into the solution. Since the rates of both reaction steps increase with increasing dissolved oxygen concentration (see table II), it is likely that both steps require $\mathrm{O}_{2}$. If the second step were slow compared to the first, the intermediate would be unable to compete with the large excess of reactant for the available dissolved oxygen, and the intermediate would continue to accumulate until the reactant was nearly depleted. The rapid decay of the initial extinction indicates that the colored intermediates are more reactive than the pyrogallol reactant.

The $\mathrm{pH}^{\prime}$ dependence of $\mathrm{k}_{1}$ fits a scheme in which neutral 4,6-di(2-phenyl-2-propyl)pytogallol, its monoanion and dianion all react with oxygen, the reaction rate increasing with the negative charge of the species. The two apparent dissociation constant obtained from the pH' dependence, $2.5 \times 10^{-13}$ and $1 \times 10^{-16}$, are reasonable values for the first and second dissociation constant of a pyrogallol in methanol. The two dissociation constants of pyrogallol in water are $9.67 \times 10^{-10}$ and $2.3 \times 10^{-12}(1)$, and the $\mathrm{pK}_{\mathrm{a}}$ values of neutral acids tend to be four to six units higher in alcohol than in water (7).

The shape of the $k_{1}$ versus $\mathrm{pH}^{\prime}$ curve is reminiscent of that found by MARKLUND and MARKLUND (17) for the rates of air oxidation of pyrogallol in aqueous alkaline solutions. These authors found proportionality between rate and hydroxide concentration below $\mathrm{pH} 9, \mathrm{pH}$ independence in the range 9-10, and a further proportional increase at higher $\mathrm{pH}, \mathrm{a}$ dependence which fits a scheme in which the pyrogallol dianion reacts more rapidly than the monoanion. The apparent differences between the current results and those of MARKLUND and MARKLUND may be due to unsolved experimental difficulties in our work. The first difference is that the increase in rate at high $\mathrm{pH}^{\prime}$ is not as large as found for pyrogallol. This may be in error because of the difficulty in measuring the rapid reactions in the more concentrated sodium methoxide solutions and the fact that the kinetic curves at very high $\mathrm{pH}$ ' did not fit eqn. 1 over the entire course of the reaction. The other difference, the slow neutral reaction observed in the current work, may be due to trace metal ion contamination. MARKLUND and MARKLUND, having observed such a reaction, suppressed it with EDTA. Because of the insolubility of EDTA salts in methanol, this procedure was not applicable to the present work. We have observed that neutral solutions of 4,6-di(2-phenyl-2-propyl)pyrogallol in technical grade methanol darken more rapidly than solutions in reagent grade solvent.

The $\mathrm{pH}^{\prime}$ dependence of $\mathrm{k}_{2}$ is nearly identical to that of $k_{1}$. This similarity indicates that the intermediate responsible for extinction is a diprotic acid with dissociation constants similar to those of the pyrogallol. Furthermore, the relative reactivities of the neutral intermediate, its anion and dianion appear to resemble those of the various protonation forms of the pyrogallol. Since the 3-hydroxy-o-quinone (Fig. 1, III) has only one dissociable proton, it is unlikely that this species is solely responsible for either extinction band. The corresponding semiquinone (IV), with two acidic hydrogens and an electronic structure similar to the pyrogallol, provides a far better model for the pH' dependence.

Electron spin resonance signals of semiquinones have been observed during the air oxidation of alkaline pyrogallol solutions (14), and of 4,6-di-tert-butylpyrogallol in alkaline dimethylformamide (21). REIN and RISTAU (22) have observed the kinetics of semiquinone formation during the iodate oxidation of pyrogallol in aqueous solutions. Their results indicate two consecutive second order processes, both involving an oxidant molecule.

The $770 \mathrm{~nm}$ extinction appears to be due to the conjugate base of a species with a dissociation constant of about $2 \times 10^{-13}$. The apparent $\varepsilon$ values at $770 \mathrm{~nm}$, based on an assumed two-step process and a $\mathrm{pH}$ ' independent $\mathrm{k}_{2} / \mathrm{k}_{1}$ ratio, fit a sigmoid curve when plotted versus $\mathrm{pH}$, and the inflection point for this curve is about pH' 12.7. 
Rapid acidification experiments show that the reaction of the $770 \mathrm{~nm}$ species with acid is, as expected for a proton transfer, too fast to measure in our experiments. In view of the agreement between the inflection point $\mathrm{pH}^{\text {, }}$ and the value of the first dissociation constant found from the $\mathrm{pH}$ ' dependence of $\mathrm{k}_{2}$, the most reasonable hypothesis is that the $770 \mathrm{~nm}$ extinction is due to the semiquinone monoanion.

We have assumed that the mechanism involves consecutive bimolecular reactions with $\mathrm{O}_{2}$, but more complex reaction schemes deserve consideration. One such possibility is bimolecular disproportionation of the semiquinone. VARTANYAN et al. (28) have proposed a reversible, base induced semiquinone disproportionation to explain an apparent paradox in the kinetics of air oxidation of propyl gallate. These authors found that the observed oxidation rates were constant with time for up to $50 \%$ reaction even though the initial oxidation rates were proportional to the propyl gallate concentration. On the other hand, REIN and RISTAU (22) found that the rate of decay of pyrogallol semiquinone in base is strictly proportional to iodate concentration, an indication that the semiquinone is relatively stable and does not decay by non-oxidative pathways.

Our data show little or no evidence of an irreversible disproportionation of the $770 \mathrm{~nm}$ intermediate or its reversible formation of a dimer which then reacts with oxygen. Either of these cases would produce a kinetic system in which an irreversible second-order or pseudo second-order process follows an irreversible pseudo first-order process. TALAT-ERBEN (26) has shown that in such systems $k_{1} t_{\max }$ decreases sharply and $(B)_{\max } /(A)_{0}$ decreases gradually as $(A)_{0}$ is increased. Neither of these effects occurs at high $\mathrm{pH}$, while the evidence for changes in $\mathrm{k}_{1} \mathrm{t}_{\max }$ or $\mathrm{E}_{\max } /(\mathrm{A})_{0}$ at low $\mathrm{pH}^{\prime}$ is marginal.

If the $770 \mathrm{~nm}$ intermediate is the semiquinone, the current results support the conclusions of REIN and RISTAU (22) concerning the absence of irreversible semiquinone disproportionation. Although the reversible disproportionation proposed by VARTANYAN et al. (28) can also fit the apparent constancy of $\mathrm{k}_{1} \mathrm{t}_{\max }$ and $\mathrm{E}_{\max } /(A)_{0}$, the evidence in support of this hypothesis is weak. It is based on observations of a reaction with oxygen gas, and complications involved in the rate of diffusion of $\mathrm{O}_{2}$ from the gas bubbles into the solution may be the source of the apparent kinetic paradox. Since diffusion from gas bubbles into a reactant solution is a very complicated kinetic system, the observation that oxidation rates were independent of the rate of introduction of $\mathrm{O}_{2}$ does not disprove the significance of diffusion effects.

Several authors (for example, 23) describe colorless dimers of the o-quinone, and NishinaGA et al. (21) report that the dimer formed by oxidation of 4,6-di-tert-butylpyrogallol decomposes to the semiquinone in alkaline dimethylformamide. These observations raise the possibility that an intermediate is in equilibrium with a colorless dimer that does not lie on the oxidation pathway.



If such an equilibrium strongly favored the dimer, $E_{\max }$ would be proportional to the square root of the initial reactant concentration. The data in table I do not show this effect.

It is difficult to explain the $\mathrm{pH}^{\prime}$ dependence of $\varepsilon$ at $500 \mathrm{~nm}$. Rapid acidification of a partially oxidized solution of 4,6-di-(2-phenyl-2-propyl)pyrogallol does not produce an immediate decrease in extinction at $500 \mathrm{~nm}$, so the lower extinction coefficients at lower $\mathrm{pH}$ ' are not due to an acid-base equilibrium of the intermediate. The kinetic curve for the extinction changes of a rapidly acidified solution fits the integrated rate equation for a two-step reaction in which the initial concentration of intermediate, $(B)_{0}$, is greater than the maximum concentration attainable by oxidation at the low $\mathrm{pH}^{\prime}$ :

$$
\begin{aligned}
& \text { (B) }=\frac{k_{1}(A)_{0}}{k_{2}-k_{1}} e^{-k_{1} t}+\left[(B)_{0}-\frac{k_{1}(A)_{0}}{k_{2}-k_{1}}\right] e^{-k_{1} t} \\
& (B)_{0}>\frac{k_{1}(A)_{0}}{k_{2}-k_{1}}
\end{aligned}
$$


The difficulty is that since there is no apparent change in $\mathrm{k}_{2} / \mathrm{k}_{1}$ with $\mathrm{pH}$, it is hard to see how the concentration of $\mathrm{B}$ accumulating at high $\mathrm{pH}$ ' could be greater than the maximum concentration at low $\mathrm{pH}$ '.

The explanation of the effect of $\mathrm{pH}^{\prime}$ on $\mathrm{E}_{\max }$ at $500 \mathrm{~nm}$ may lie in a more complex mechanistic scheme, but we have been unable to develop a mechanistic proposal that deals with the observations satisfactorily. We will consider two such schemes and their indequacies.

The first scheme is a three-step reaction in which the $500 \mathrm{~nm}$ intermediate is formed from the $770 \mathrm{~nm}$ intermediate or its conjugate acid.

The first scheme is a three-step reaction in which the $500 \mathrm{~nm}$ intermediate is formed from the $770 \mathrm{~nm}$ intermediate or its conjugate acid.
$\mathrm{A} \stackrel{\mathrm{k}_{1}}{\longrightarrow} \underset{770}{\mathrm{~B}} \stackrel{\mathrm{k}_{2}}{\longrightarrow} \underset{500}{\mathrm{C}} \stackrel{\mathrm{k}_{\mathbf{3}}}{\longrightarrow} \begin{aligned} & \text { colorless } \\ & \text { products }\end{aligned}$
$(C)=k_{1} k_{2}(A)_{0}\left[\frac{e^{-k_{1} t}}{\left(k_{2}-k_{1}\right)\left(k_{3}-k_{1}\right)}-\frac{e^{-k_{2} t}}{\left(k_{2}-k_{1}\right)\left(k_{3}-k_{2}\right)}+\frac{e^{-k_{3} t}}{\left(k_{3}-k_{1}\right)\left(k_{3}-k_{2}\right)}\right]$

(scheme 1)

In order for this scheme to fit the observed kinetics, $k_{3}$ must be much larger than $k_{2}$. Otherwise, the formation of the $500 \mathrm{~nm}$ intermediate would lag behind the formation of the $770 \mathrm{~nm}$ species, and the kinetic curves at $500 \mathrm{~nm}$ would have inflection points on their ascending sides. Neither of these effects is apparent in the data. If $\mathbf{k}_{\mathbf{3}} / \mathbf{k}_{\mathbf{2}}$ were large, the kinetics at $500 \mathrm{~nm}$ would approximate those at
$770 \mathrm{~nm}$. Furthermore, changes in $\mathrm{k}_{3} / \mathrm{k}_{2}$ would affect $E_{\max }$ at $500 \mathrm{~nm}$ without altering the ratio of the apparent rate constants. However, rapid acidification experiments definitely rule out the possibility of large $k_{3}$ values. According to the integrated rate equation for scheme 1 in which the initial concentration of the reactant and the two intermediates are $(\mathrm{A})_{0},(\mathrm{~B})_{0}$ and $(\mathrm{C})_{0}$ respectively,

$(C)=\frac{k_{1} k_{2}(A)_{0} e^{-k_{1} t}}{\left(k_{2}-k_{1}\right)\left(k_{3}-k_{1}\right)}+\frac{k_{2}}{k_{3}-k_{2}}\left[(B)_{0}-\frac{k_{1}(A)_{0}}{k_{2}-k_{1}}\right] e^{-k_{2} t}+\left[(C)_{0}+\frac{k_{1} k_{2}(A)_{b}}{\left(k_{3}-k_{1}\right)\left(k_{3}-k_{2}\right)}\right] e^{-k_{3} t}$

After acidification of a partially oxidized solution, the extinction would decay with an initial rate $\left(\mathrm{k}_{3}\right)$ that is much faster than the rates apparent from the oxidation at the low $\mathrm{pH}$ '. No such rapid initial decay occurs, and the kinetic constants for decay of the acidified solution match those found for oxidation at the low $\mathrm{pH}$ '.

The second scheme involves parallel reactions.

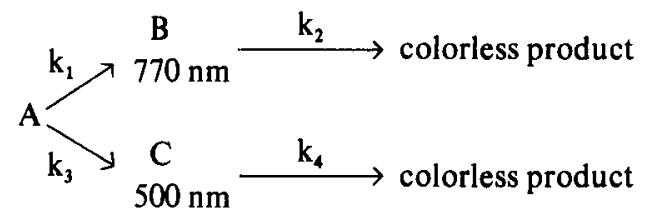

(scheme 2)

$$
\begin{aligned}
& (B)=\frac{k_{1}(A)_{0}}{k_{2}-k_{1}-k_{3}}\left[e^{-\left(k_{1}+k_{3}\right) t}-e^{-k_{2} t}\right] \\
& (C)=\frac{k_{1}(A)_{0}}{k_{4}-k_{1}-k_{3}}\left[e^{-\left(k_{1}+k_{3}\right) t}-e^{-k_{4} t}\right]
\end{aligned}
$$


Because of the indistinguishable kinetics at 500 and $700 \mathrm{~nm}, \mathrm{k}_{2}$ and $\mathrm{k}_{4}$ would have to be nearly identical. The attractive feature of scheme 2 is that, if $\mathbf{k}_{\mathbf{3}}$ were much smaller than $k_{1}$, changes in the $k_{3} / k_{1}$ ratio would not affect the ratio of the apparent kinetic constant but would influence the maximum concentration of C.

$$
\text { (B) } \max =\frac{k_{1}(A)_{o}}{k_{1}+k_{3}} \quad r^{-r / r-1}
$$$$
(C)=\frac{k_{3}(A)_{0}}{k_{4}-k_{1}-k_{3}} e^{-\left(k_{1}+k_{3}\right) t}+\left[(C)_{0}-\frac{k_{3}(A)_{0}}{k_{4}-k_{1}-k_{3}}\right] e^{-k_{4} t}
$$

$(C)_{\max }=\frac{k_{3}(A)_{o}}{k_{1}+k_{3}} r^{-r / r-1}$

where $r=\frac{k_{2}}{k_{1}+k_{3}} \sim \frac{k_{4}}{k_{1}+k_{3}}$

Changes in $k_{3} / k_{1}$ could have a large effect on $E_{\max }$ at $500 \mathrm{~nm}$ but practically no influence at $770 \mathrm{~nm}$. The equation for decay after acidification can easily be accomodated to the experimental data, the high $(\mathrm{C})_{0}$ value being explained by a larger $\mathrm{k}_{3} / \mathrm{k}_{\mathbf{1}}$ value at high $\mathrm{pH}$.

The difficulties with scheme 2 arise when one attempts to substitute molecular structures for the abstract symbols of the kinetic system. It hardly seems reasonable that $B$ and $C$, having different structures, would show identical rate constants for decay over such a wide $\mathrm{pH}$ ' range. It is particularly improbable since one of the more likely intermediates, the 3-hydroxy$o$-quinone (Fig. 1, III), is a monoprotic acid incapable of the second dissociation required by the $\mathrm{pH}^{\prime}$ dependence of $\mathrm{k}_{2}$ at $500 \mathrm{~nm}$. Furthermore, a two-electron oxidation of the pyrogallol to its $o$-quinone is highly improbable because of spin restrictions on electron transfer from triplet $\mathrm{O}_{2}$ to a singlet organic molecule (27). Finally, it is hard to imagine how the 770 $\mathrm{nm}$ intermediate, if it is a semiquinone, could react with oxygen and not form the quinone.

A more likely explanation is that the $500 \mathrm{~nm}$ extinction arises from at least two distinct, non-equilibrating species, one of which is the species absorbing at $770 \mathrm{~nm}$ or its conjugate acid. Extinction due to the $770 \mathrm{~nm}$ species could obscure the kinetics of the nonequilibrating species. One piece of evidence that at least two species are contributing to extinction at $500 \mathrm{~nm}$ is the downward shift in $\lambda_{\max }$ of the $500 \mathrm{~nm}$ peak with time when air oxidation occurs in the presence of deficient dissolved oxygen (Fig. 5).

The most likely candidate for the non-equilibrating $500 \mathrm{~nm}$ species is the 3-hydroxy-o-quinone. Although pyrogallol oxidation produces polymeric products such as diphenyls (12) and triphenoquinones (19), these products and the polymeric intermediates leading to them do not appear to be important in the case of pyrogallols containing bulky substituents in the 4 and 6 positions. The rationale behind the first studies of the air oxidation of 4,6-di-tert-butylpyrogallol (24) was the presumed steric suppression of polymerization, and all the air oxidation products are monomeric (9). The isolated products of the air oxidation of 4,6-di(2-phenyl-2-propyl) pyrogallol, comprising over $60 \%$ of the theoretical yield, are also monomeric (2).

The possibility that species other than triplet $\mathrm{O}_{2}$ oxidizes a colored intermediate deserves consideration. MARKLUND and MARKLUND (17) have demonstrated superoxide involvement in the air oxidation of pyrogallol in weakly basic solutions. Meluzova and VASSILEV (18) have interpreted the chemiluminescence accompanying the oxidation of pyrogallol in alkaline solutions as an indication of the transient formation of singlet $\mathrm{O}_{2}$. DosKOCIL (10) and VARTANYAN et al. (28) have detected 
hydrogen peroxide in pyrogallol oxidation by polarographic and chemical means.

The insensitivity of $k_{2} / k_{1}$ to oxygen concentration argues against a scheme of the sort

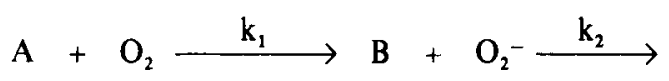

in which superoxide is the sole oxidant of B, and the only fate of the superoxide is to react with $B$. In such a case, the superoxide concentration would always equal (B). Increased oxygen concentration does not alter the maximum concentration of the intermediate but does increase $\mathrm{k}_{2}$, a result that is inconsistent with the proposed scheme. The effect of oxygen concentration might be consistent with superoxide involvement if the majority of the superoxide ions undergo dismutation. In such a case, increased oxygen concentration would raise the steady state concentration of superoxide and increase $\mathrm{k}_{2}$.

The air oxidation mechanism probably involves subsequent oxidation steps not involving detectable concentrations of colored intermediates since it requires the removal of four electrons to oxidize the pyrogallol reactant to its major oxidation product 3,5-di(2-phenyl2-propyl)2pyrone-6-carboxylic acid (Fig. 1, II) (2). The reaction must either involve a complex system of one-electron transfers and possibly disproportionations, or two-electron transfers must occur. The latter possibility is unlikely in view of electron spin restrictions.

\section{ACKNOWLEDGEMENTS}

Preliminary kinetic and spectroscopic investigations were ably performed by $\mathrm{L}$. K. WONG. We would like to thank JACK JOHANSEN for the loan of the rapid mixing apparatus and LISBETH SEJERSEN for writing the computer program for evaluation of rate constant and extinction coefficients.

\section{REFERENCES}

1. Abichandani, C. T \& S. K. K. JatKar: Dissociation constants of $o-, m$ - and $p$-hydroxybenzoic acids, gallic acid, catechol, resorcinol, hydroquinone, pyrogallol and phloroglucinol. J. Indian Inst. Sci. 21A, 4.7-441 (1938)

2. Abrash, H. I. \&. C. NiemanN: Steric hindrance in $\alpha$-chymotrypsin-catalyzed reaction. Biochemistry $2,847-853(1963)$

3. Alcock, N. W., D. J. Benton \& P. Moore: Kinetics of series first-order reactions. Analysis of spectrophotometric data by the method of least squares and an ambiguity. Trans.Faraday Soc. 66, 2210-2213(1970)

4. Auld, D. S. \& T. C. FrenCh: Cell for spectrophotometric titrations with small volumes. Anal. Biochem. 34, 262-274 (1970)

5. Bates, R. G.: Determination of pH. Theory and Practice, John Wiley \& Sons (New York) pp. 222-229 (1964)

6. ibid.p. 183.

7. ibid.pp. 151-152.

8. Broser, W. \& H. Fleischauer: Substituenteffekte bei Triphenylmethanfarbstoffen II. Eine Pufferreihe für das methanolische Medium.

Z. Naturforsch. 25b, 1389-1394 (1970)

9. Campbell, T. W.: The oxidation of di-t-butylpyrogallol by oxygen in alkaline solution. J. Am. Chem. Soc. 73, 4190-4195 (1951)

10. Doskocil, J.: Polarography of some orthophenols and their oxidation products. Collect. Czechoslov. Chem. Commun. 15, 599-613 (1950)

11. Frost, A. A. \& R. G. Pearson: Kinetics and Mechanism, John Wiley \& Sons (New York) p. 155 (1953)

12. Harries, C:: Ueber die Autoxydation des Pyrogallols. Chem. Ber. 35, 2954-2959 (1902)

13. Hathway, D. E.: Autoxidation of polyphenols. I. Autoxidation of methyl gallate and its O-methyl ethers in aqueous ammonia. J. Chem. Soc. 519-523 (1957)

14. Hoskins, R. H. \& B. R. LoY: Paramagnetic resonance in solutions of oxidized pyrogallol. J. Chem. Phys. 23, 2461-2462 (1955)

15. Washburn, E. W., ed.: International Critical Tables of Numerical Data. Physics, Chemistry and Technology, McGraw-Hill (New York) Volume III p. 262 (1928)

16. JONSSON, A: Studies on Antimetabolites. I. Syn-

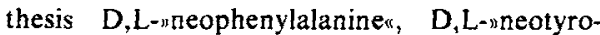
sine and $D, L-n n e o-3,5$-diiodo-tyrosine, the $\beta$, $\beta$-dimethyl analogues of optically inactive phenylalanine, tyrosine and 3,5-diiodotyrosine. Acta Chem.Scand. 8, 1203-1210(1954) 
17. Marklund, S. \& G. Marklund: Involvement of the superoxide anion radical in the autoxidation of pyrogallol and a convenient assay for superoxide dismutase. Eur. J. Biochem. 47, 469-474 (1974)

18. Meluzova, G. B. \& R. F. Vassilev: Stoichiometry of chemiluminescent oxidation of pyrogallol by oxygen in aqueous solutions. Mol. Photochem. 2, 251-257 (1970)

19. Nierenstein, M.: An oxidation product of pyrogallol. J. Chem. Soc. 107, 1217-1220(1915)

20. Nilsson, R.: On the mechanism of peroxidase catalyzed oxidations studied by means of chemiluminescence measurements. Acta Chem. Scand. 18, 389-401 (1964)

21. Nishinaga, A., T. Ithara \& T. Matsuura: Base catalyzed oxygenation of 3,5-di-t-butylpyrocatechol and its related compounds. Bull. Chem. Soc. Japan 47, 1811-1812(1974)

22. ReIN, H.\& O. RISTAU: Elektronenspinresonanz Untersuchungen über die Oxydationskinetik von Phenylverbindungen. 1. Mitteilung: Die Kinetik der Radialbildung bei der Oxydation des Pyrogallols.
Z. Phys. Chem. (Leipzig) 239, 115-123 (1968)

23. Salfeld, J.-C.: Ober die Oxydation von Pyrogallol und Pyrogallolderivaten, II, Die Konstitution dimerer 3-Hydroxy-o-benzochinone. Chem. Ber. 93, 737-745 (1960)

24. Schulze, H. \& W. Flaig: Zur Kenntnis der Huminsaüren IV, Mitteilung Über die Rirgsprengung mehrwertiger Phenole mit Sauerstoff in alkalischem Medium. Ann. 575, 231-241 (952)

25. Tabagua, I. S.: Dissociation constants of some acids in methanol and its mixtures with water. Tr. Sukhumsk. Gos. Ped. Inst. 15; 119-133. Ref. Chem. Abstracts 60, 14373d (1964)

26. Talat-Erben, M.: Displacement of the maximum in the concentration-time diagram of uni-bi, bi-uni, and bi-bimolecular consecutive reactions. J. Chem Phys, 26, 75-77 (1957)

27. TAUBE, H.: Mechanism of oxidations with $O$. J. Gen. Physiol. 49 Pt. 2, 29-50 (1965)

28. Vartanyan, L. S., L. M. Strigun \& N. M. EMANUEL: Kinetics of the autoxidation of propyl gallate in aqueous solution. Dokl. Akad. Nauk. SSSR. 148, 97-100 (1963) 